\title{
La Desintegración Social en El Señor Presidente
}

\section{INTRODUCCIÓN}

Para componer la pesadilla de El Señor Presidente, ${ }^{1}$ Miguel Angel Asturias extrae una dictadura hispanoamericana de sus nexos históricos, despoja a sus víctimas de las pocas condiciones favorables que éstas pudieron haber gozado, y luego comprime el preponderante residuo en un acelerado montaje de putrefacción social. Sin la fuerza compensadora de elcmentos positivos - por muy escasos que éstos hayan sido en el modelo original- la armazón social y humana de la dictadura ficticia se desmorona vertiginosamente. Todo en ese mundo castrado se desintegra tan pronto como nace. Luego la podredumbre vuelve a nutrirse con los inpotentes fragmentos de vida que, a modo de castigo infernal, siguen surgiendo de la nada. Aunque desaparezca el hombre particular, la humanidad queda paralizada en una destrucción perpetua.

\section{El. hNajenaminnto}

Observamos, ante todo, que los vinculos humanos más fundamentales se deshacen inmediatamentc, o no existen. Tan inesperadas son las rupturas entre parientes y amigos, que el individuo nunca se puede prevenir ni adaptar a su repentino enajenamiento. $\mathrm{Y}$ una vez efectuada, Ia separación es tan completa, que no permite restauración alguna. Otros personajes pasan por la novela sin cstablecer un solo contacto humano.

1 Miguel Angel Asturias. El señor Presidente, tercera edición, Editorial Losada (Buenos Airts, 1959). Todas las referencias y citas que siguen están tomadas de esta edición. El número entre paréntesis indica la página a la cual corresponde. 
El idiota Pelele, por ejemplo, pierde a su madre, su único ser querido, en algún pasado remoto. Cuando alguien menciona la palabra madre y le recuerda que la suya ya no existe, el Pelele se descontrola histéricamente. (10) Y los otros pordioseros, en vez de consolarlo, se divierten burlándose de su desgracia. El Pelele entonces huye, en busca de amparo, pero a donde quiera que vaya su prójimo lo rechaza: "Entraba en las casas en busca de asilo, pero de las casas lo echaban los perros o los criados. Lo echaban de los templos, de las tiendas, de todas partes." (12)

Entre los pordioseros no existe amistad alguna. Duermen juntos en el Portal del Señor, porque no les queda más remedio. A pesar de su pobreza común, los unos a los otros se tratan como animales enemigos: "Se juntaban a dormir en el Portal del Señor sin más lazo común que la miseria, maldiciendo uno de otros, insultándose a tegañadientes con tirria de enemigos que buscan pleito, riñendo muchas veces a codazos y algunos con tierra $y$ todo, revolcones, en los que tras escupirse, se mordian." (9)

Miguel Cara de Angel sale a escena sin un solo vínculo. La primera y última vez que establece un contacto es cuando se enamora de Camila Canales y se casa con ella, (219) subrepticiamente y en contra de la desintegración prevalente. Su amor, pues, constituye un hecho constructivo que el Señor Presidente, el dios, o diablo, de la destrucción, tiene que anular para mantener su dominación. Pero como el nexo ya está logrado, el Tirano espera que se consuma bien, para que duela y desgarre más cuando por fin lo rompa.

Arrebatada para siempre de su padre y de su nana Chabela, (78) y luego repudiada por sus tios, (134) Camila se aferra entrañablemente al amor de Cara de Angel. No obstante, la pareja presiente el castigo fatal, $y$, sin poderlo evitar, ambos van preparando su propia destrucción al tratar de evadirla. El uno busca refugio en el otro y así van sellando el lazo de vida que les apresta la muerte: "Y les daba tanto miedo haber corrido este peligro, que si estaban separados se buscaban, si se veían cerca se abrazaban, si se tenían en los brazos se estrechaban y además de estrecharse se besaban y además de besarse se buscaban y al mirarse unidos se encontraban tan claros, tan dichosos, que caían en una transparente falta de memoria." (252)

Ia inevitable ruptura comienza cuando la policía frustra la fuga de Cara de Angel. (278) Con simbólico desprecio, los demonios del Tirano arrancan al "favorito" su anillo de matrimonio, el eslabón que hasta entonces lo había unido a Camila: "Por un escupitajo resbaló dedo afuera el aro en que estaba grabado el nombre de su csposa." (279) 
Cara de Angel, sin embargo, no pierde las esperanzas todavía. El jefe de la patrulla es el Mayor Farfán, a quien Cara de Angel, en otra ocasión, le había salvado la vida. El ex favorito espera que el Mayor le devuelva el favor, siquiera informándole a Camila lo que ha sucedido: "Por" lo menos que mi mujer sepa que me pegaron dos tiros, me enterraron y parta sin novedad." (280) La dictadura lo podrá matar físicamente, pero no lo puede destruir del todo mientras él y Camila permanezcan espiritualmente unidos. Por eso es tan importante para el prisionero que su esposa sepa que él no la abandonó, y, por otra parte, tan necesario para sus victimarios que ella crea lo contrario. La policía, pues, lo detiene incomunicado, e inmediatamente lo encierra en un calabozo solitario. (291)

Cara de Angel pronto queda reducido a un espectro ambulante. Sólo lo mantiene vivo el recuerdo de Camila: "Lo único y lo último que alentaba en él era la esperanza de volver a ver a su esposa." (295) La víctima, pues, está ya lista para recibir el golpe final. Un agente secreto, la única voz humana que oye desde el día de su encarcelamiento, le comunica que Camila, por venganza, se había hecho amante del Señor Presidente. Al oir la mentira, lo poco que queda del reo termina de desintegrarse: "Una telaraña de polvo húmedo había caído al suelo." (296)

Fedina Rodas sufre el suplicio de no poderle dar de mamar a su hijo, que está llorando de hambre al otro lado de una puerta de hierro. (120) El niño por fin muete (154) y la muchacha, medio loca, va a parar a un hospital. (283) Alli se encierra y nunca más vuelve a ver a su esposo Genaro.

La señora de Carvajal presiente la destrucción de su marido a través de los muros del presidio que los separa. (229) Pero no puede verlo. La policía ni siquiera le permite que se consuele con la posesión del cadáver. (237)

Don Benjamín, el titiritero, y su esposa doña Venjamón se odian. (57) Juan y Judith Canales, al desamparar a su sobrina, experimentan un irrevocable vacío de conciencia en su matrimonio. (111) El doctor Luis Barreño ha perdido el amor y respeto de su esposa, y también su fidelidad, pues ésta lo había estado engañando con el asesino de su padre. (36)

La Masacuata pierde a Lucio Vázquez tan pronto como se enamora de él. (128) "Ese animal" queda tan bien castigado que no vuelve a ver a su familia. (38) Esposas y madres esperan, sin esperanza alguna, a los numerosos prisioneros políticos encerrados en las mazmorras de la Dictadura. (14)

La acción destructura no permite, sobre todo, que exista el amor mater- 
no, el nexo humano más fundamental, y el origen de la vida misma. El Pelele, Camila, Cara de Angel, y aun el Presidente, pierden sus respectivas madres en algún pasado bortoso. A la mayoría de los personajes femeninos no se le conocen hijos: Chabela, la Masacuata, doña Venja. món, Judith Canales, la señora de Barreño, las tres hermanas solteras, (198) las enfermeras de Camila, (219) doña Chón, las prostitutas del Dulce Encanto.

En el Portal del Señor una de las pordioseras llora enloquecida porque siente un hijo en las entrañas. (10) El Pelele nace a modo de enfermedad que destruye a su madre y repugna al borracho que la preñó: "En su agonía se juntaton la cabeza desproporcionada de su hijo - una cabezota redonda y con dos coronillas como luna- las caras huesudas de todos los enfermos del hospital y los gestos de miedo, de asco, de hipo, de ansia, de vómito del gallero borracho." (25)

La vida naciente se trueca repentinamente en muerte cstéril cuando la Dictadura prohibe que Niña Fedina alimente a su hijo. El bautizo del niño, que iba a celebrarse en esos días, (113) es sustituido por un grotesco velorio en el cual las prostitutas del Dulce Encanto reciben al cadáver como hijo adoptivo: "Todas querían ver y besar al niño, besarlo muchas veces, y se lo arrebataban de las manos, de las bocas. Una máscara de saliva de vicio cubrió la carita arrugada del cadáver, que ya olía mal." (160)

Una de las numerosas viejas anónimas que esperan inútilmente a sus hijos, resume con su llanto perenne la esterilidad humana bajo la Dictadura: "Una anciana palúdica y ojosa se bañaba en lágrimas, callada, como dando a entender que su pena de madre era más amarga." (14)

La única unión materna que parece lograrse es la de Camila y Miguelito. Pero para ello, madre e hijo tienen que salir de la ciudad; es decir, del ambiente de la novela. (290)

\section{LA DESUNIÓN}

Fuera de los lazos evanescentes entre seres queridos y los encuentros cacofónicos entre víctimas y verdugos, los personajes generalmente se desconocen o se ignoran. Aunque casi todos están directa o indirectamente eslabonados en el encadenamiento de sucesos desatado por el asesinato de Parrales Sonriente, la mayoría de ellos obran como si estuvieran completamente desconectados. $\mathrm{Y}$ la poca comunicación que existe está tan obstruida por la mentira, el miedo, la locura, que apenas se entienden. Tales encuentros, además, suelen ser efímeros, y los interlocutores, en la 
mayoría de los casos, no se vuelven a encontrar. La idea de cooperación, de acción colectiva, por consiguiente, no existe en El Señor Presidento. Los personajes transitan por la novela totalmente solos, como impotentes nulidades perdidas en una turba invisible.

En una cita que acontece fuera de escena, Cara de Angel y el General Canales trazan un plan que ambos consideran absurdo, pero, debido a la duplicidad de las circunstancias, el único factible: "Aquello no tenía pics ni cabeza, y si cl general y el favorito, a pesar de entenderlo así lo cncontraron aceptable, fue porque uno y otro lo juzgó para sus adentros trampa de doble fondo." (73)

El favorito y el general, pues, están juntos pero fuera de contacto. Este mismo plan constituye el terreno común de comunicación entre Cara de Angel, Lucio Vázquez, la Masacuata y la pandilla de maleantes contratada por el favorito. (75) Vázquez, además, finge creerse la mentira de Cara de Angel, pero sospecha otra cosa, (52) que tampoco es cierto. $Y$ como no le comunica esta sospecha a la Masacuata, su amante, los miembros del grupo están maquinando juntos, pero actuando por separado.

El leñador que ayuda a Cara de Angel a sacar al Pelele del basurero, no está colaborando con el favorito sino con lo que él cree que es un ángel. (29) Pelele, a su vez, no sabe quiénes son sus benefactores, y viceversa. Cara de Angel y Genaro Rodas se encuentran una sola vez, y no se hablan. (282) El favorito previene al mayor Farfán cuando éste está borracho y no habla ni oye bien. (183) Luego Farfán le corresponde con una brutal paliza. (282) Cara de Angel, por otra parte, no le había hecho el favor a Farfán por amistad, sino para redimirse él ante Dios con un falso acto de caridad. (180)

La única conversación entre el favorito y doña Chón carece de unidad, porque ambos quieren tratar asuntos distintos. $\mathrm{El}$ uno no pone nin. guna atención a lo que el otro dice, y en el único momento de interés mutuo, cuando doña Chón le cuenta a Cara de Angel lo acaecido a Niña Fedina, Cara de Angel confunde a la muchacha con la criada de Camila, lo cual indica que el favorito no estaba enterado de la muerte de Chabela y desconocía quièn era Fedina Rodas. (172-176)

El favorito, sin embargo, nunca se entera, porque pierde interés en ellas tan pronto como deja a doña Chón. Asimismo se olvida de todo el mundo. Después de su matrimonio, menciona al general Canales una sola vez, y nunca más menciona a Lucio Vázquez o a la Masacuata. La única conversación entre el favorito y los tíos de Camila se desarrolla a través de un vacio infranqueable. (110) 
Ahora bien: si el personaje más peripatético y ubicuo de la novela sólo logra unos contactos efímeros, los otros apenas salen de su arslamiento. Camila, por ejemplo, sólo se ve hablando en dos breves ocasio. nes con la propietaria de la taberna en donde se esconde la mayor parte de la novela. (87) (129) A Lucio Vázquez no le dirige una sola palabra. Después de su matrimonio no los vuelve a mencionar. Su vínculo con Niña Fedina - ella le había prometido ser la madrina del niño(64) existió en un pasado desconocido. Camila nunca se entera de la desgracia de Fedina.

Fedina, a su vez, deja de hablar después de la muerte de su hijo. (155) El Pelele no puede comunicarse con nadie porque es idiota y mudo. (51) Entre Carvajal y sus compañeros de celda hay tanta distancia comunicativa que la conversación desarticulada entre ellos aparece como tres voces anónimas en la oscuridad. (207) A pesar de su supuesta complicidad en el asesinato de Parrales Sonriente, Carvajal y Canales nunca se cruzan, ni se mencionan.

Perdidos en su desunión, Chabela no se entera de la fuga del general Canales, el Auditor no sabe que el favorito está obrando bajo las órdenes del presidente, (139) Cara de Angel no se da cuenta que es vigilado por Genaro Rodas (243) y espiado por sus dos criadas, una de las cuales no sospecha que es espiada por la otra: "Alli; la cocinera que espiaba al amo y a la de adentro que espiaba al ama $y$ a la cocinera..." (69)

El general Canales, aparentemente, es el único personaje que logra la cooperación de sus semejantes. Cára de Angel le salva la vida, un indio lo conduce hasta la casa de sus tres amigas, (197) éstas lo protegen y allanan los últimos obstáculos de su fuga, (201) un contrabandista anónimo lo lleva al otro lado de la frontera. (203) Y la progresión positiva parece consumarse cuando Canales organiza el ejército rebelde y se apresta a liberar al país. (259)

En la superficie, como parte del argumento, la esperanza despertada por Canales reside sencillamente en la fuerza potencial de su ejército. Pero en un nivel dimensional, dentro del proceso destructor detrás del argumento, dicha esperanza estriba en el aparente éxito del esfuerzo colectivo, el único en la novela.

Pero todo tesulta ser falso. Las fuerzas rebeldes se organizan fuera de escena, y se desintegran en cuanto surgen ante el lector. (260) Sabemos que se logró algo, pero nunca lo vemos, en ningún nivel. No hay ni acción colectiva visible ni revolución. Canales muere el mismo día de la invasión y el ejército libertador se dispersa irremediablemente. (261) 


\section{LA MENTIRA}

En su estado de desunión, los personajes, claro está, no pueden mantener un criterio unánime de la verdad. De ahí que cuando hablan o actúan, casi siempre están pensando o haciendo otra cosa. Sus efímeros contactos, por consiguiente, generalmente se basan en suposiciones falsas $o$, si captan el engaño, en más mentiras y contramentiras.

El encadenamiento de duplicidades comienza cuando el Gobierno oficialmente acusa a Abel Carvajal y a Eusebio Canales del asesinato del coronel Parrales Sonriente. Los pordioseros, testigos del crimen, al principio tratan de declarar la verdad, que Pelele fue el asesino. (17)

Pero la policía pronto los convence de que la versión falsa del Gobierno es la verdadera. El Mosco, el único que insiste en decir la verdad, es inmediatamente exterminado y transportado al populoso cementerio en un carretón de basuras. (19)

La reacción idiota del Pelele es entonces borrada y reemplazada por una crisis nacional inventada por el Estado: "El proceso seguido contra Canales y Carvajal por sedición, rebelión y traición con todos sus agravantes, se hinchó de folios; tanto que era imposible leerlo de un tirón." (213)

Los pordioseros ahora aseveran que vieron a los acusados estrangular a Parrales Sonriente, y acto seguido oyeron a Carvajal decir a Canales: "Ahora que ya quitamos del medio al de la mulita, los jefes de los cuarteles no tendrán inconveniente en entregar las armas y reconocerlo a usted, general, como Jefe Supremo del Ejército, corramos pues... para que se proceda a la captura y muerte del Presidente de la República y a la organización de un nuevo gobierno." (213) La mentira, pues, crece con esta admirable memoria que el Estado le atribuye a sus bestializados testigos.

Cuando el Presidente le encarga a Cara de Angel la maquinación de la fuga de Canales, le da a entender que al Gobierno no le conviene que la policía lo capture. "Corre a buscarlo, cuéntale lo que sabes y aconséjale, como cosa tuya, que se escape esta misma noche... ni él debe saber esta conversación, solamente tú y yo." (41)

Cara de Angel, desde luego, se da cuenta de que el Tirano está preparando una trampa: "A este hombre lo van a asesinar al salir de su casa -...un medio ingenioso para dar al crimen cariz legal... (74)

El favorito, sin embargo, está bien adiestrado en el juego de mentiras, según podemos apreciar por su puesto y por la hipocresía con que suele ablandar al Amo: "Extraño, ya lo creo, para un hombre de la vasta 
ilustración del Señor Presidente, que con sobrada razón se le tiene en el mundo por uno de los primeros estadistas de los tiempos modernos." (231) Siguiendo, pues, su modo de ser, pero esta vez dejándose guiar por su conciencia, el favorito se empeña en frustrar los planes del Tirano sin desobedecer sus órdenes. (74)

Para ello, acuerda con una pandilla de delincuentes que si ellos le ayudan a raptar a Camila, él les dejará que saqueen la casa del general. Cara de Angel les explica que la muchacha, para desorientar a su padre, gritará " $j$ ladrones!" tan pronto los oiga subir al techo. (73) Este plan tan absurdo, aun para sus autores, constituye, entonces, una serie de mentiras dentro de mentiras, ya que todo el mundo estará fingiendo.

La verdadera intención de Cara de Angel, desde luego, es crear la mayor confusión posible para que Canales salga inadvertido. $Y$ efectivamente, cuando la pandilla asalta la casa, los polizontes que patrullan las calles olvidan sus órdenes y se confunden con los delincuentes para colaborar en el saqueo. (78)

Al otro día Cara de Angel visita a Juan Canales para tratar el asunto del traslado de Camila, su sobrina. Pero don Juan, acobardado, se apresura a contestarle que él y su hermano no se llevaban bien: "Estábamos distanciados desde hacia mucho tiempo con mi hermano, que éramos como enemigos... isi, como enemigos a muerte; él no me podía ver ni en. pintura y yo menos a él!" (109) Don Juan, además, reprocha el crimen de su hermano e insiste en su lealtad cívica. (103)

Dicha declaración, sin embargo, no coincide con la versión de Ca. mila: "Es Juan el hermano a quien más ha querido mi papá. Siempre me dijo: 'cuando yo falte, te dejaré con Juan, y a él debes buscar y obedecer como si fuera tu padre.' Todavía el domingo comimos juntos." (126)

Don Juan, además, censura la oferta que, según él, su hermano le había hecho al Presidente para salvarse el pellejo. "Ofreció... ¿cómo dijéramos?... sí, a su hija a un intimo amigo del Jefe de la Nación..., quien a su vez debía of recerla al propio Presidente." (110) El general Canales, claro está, era incapaz de tal infamia. Pero la infamia cortió como verdad.

El vinculo matrimonial de Cara de Angel y Camila es destruido por tres mentiras oficiales. La primera aparece en el periódico unos días después de la boda: "Boda en el gran mundo. Ayer por la noche contrajeron matrimonio la bella señorita Camila Canales y el señor don Miguel Cara de Angel... boda que fue apadrinada ante la ley por el Excelentísimo Señor Presidente Constitucional de la República, en cuya casa ha- 
bitación tuvo lugar la ceremonia... y por los apreciables tíos de la novia don Juan Canales y don José Antonio del mismo apellido." (234)

Los amantes, que en verdad se habian casado sobrepticiamente en la taberna de la Masacuata, emprenden su breve vida conyugal con la advertencia de que es imposible actuar fuera de la norma destructora de la Dictadura. Esta misma mentira sirve a la vez para matar de pena al General Canales, (261) y para remorder la conciencia de Camila, cuando ésta se entera de que su padre creyó que ella lo habia traicionado. (262)

Luego, cuando el lazo conyugal parece estar bien ligado, el Presidente desenvaina su segunda mentira, la falsa misión diplomática a los Estados Unidos. (279) "Los periódicos publicarán mañana la noticia de tu próxima partida", (271) le comunica el Tirano a su víctima.

El exfavorito por fin es aniquilado cuando el prisionero en la celda contigua, situado allí para clavarle la última mentira, le cuenta el motivo de su encarcelación: "Habia querido enamorar a la prefe... del Señor Presidente, una señora que, según supo, antes que lo metieran a la cárcel por anarquista, era hija de un general y hacía aquello por vengarse de su marido que la abandonó." (296) Cara de Angel, claro está, no la abandonó, y Canales nunca fue encarcelado.

Lucio Vázquez extermina al Pelele porque, según las autoridades, el idiota sufría de rabia y los médicos habian recetado "que se le introdujera en la piel una onza de plomo". (51) Cuando la policía detienc a Vázquez por administrar la dosis prescrita, el matón declara que él estaba obrando bajo órdenes secretas del Señor Presidente. (144) Pero como Vázquez no puede proveer pruebas de las órdenes por escrito, el Auditor de Guerra lo condena a muerte. El Tirano, aparentemente, le había man. dado a Vázquez que devolviera las órdenes para así evitarse compromisos en la muerte del verdadero asesino de Parrales Sontiente, y, al mismo tiempo, eliminar legalmente al verdugo. (144) Vázquez y el idiota, desde luego, obstruian con sus meras presencias el sistema de mentiras elaborado en torno al crimen.

Puesto en libertad inesperadamente, Genaro Rodas sale tan contento que no lee el documento que el Auditor de Guerra le da para firmar. Rodas, desde luego, supone que tiene que ver algo con su absolución, pero el documento, en verdad, dice que él, Genaro Rodas, recibió de doña Concepción Gamucino la suma de 10000 pesos por los daños que ésta le había causado con la perversión de su esposa, Niña Fedina, en el Dulce Encanto. (243)

Doña Cbón, en efecto, había pagado 10000 pesos por Niña Fedina, pero no a Genaro, sino al Auditor de Guerra, quien le había vendido la 
muchacha. Pero como Fedina no le dio resultado, doña Chón reclama al Auditor sus 10000 pesos, y como éste se niega a devolvérselos, la madama amenaza con darle las quejas al Señor Presidente. El Auditor, sin embargo, le tapa la boca con el documento firmado por Genato Rodas.

El Presidente, por otra parte, le dice a Cara de Angel que Camila era la muchacha que el Auditor le había querido vender a doña Chón: "El Auditor de Guerra, de acuerdo con la policía, pensaba raptar a la que ahora es tu mujer y venderla a la dueña de un prostibulo, de quicn, tú lo sabes, tenía diez mil pesos recibidos a la cuenta." (270)

El Auditor, como hemos visto, es capaz de todo, pero en el caso de Camila no pudo haber tramado nada porque nunca estuvo enterado del plan de fuga de Cara de Angel ni del paradero de la muchacha. El negocio fue idea de doña Chón, y afectaba sólo a Niña Fedina. (137) Camila nunca fue regalo ni estuvo en venta.

El. doctor Luis Barreño no puede ejercer su profesión de ciencias en un mundo donde la verdad suele ser mentira y viceversa. Sus investigaciones muestran que el laxante barato usado en el hospital le estaba perforando el intestino a los enfermos. Para robarse algunos pesos del presupuesto, el Jefe de Sanidad Militar estaba tonificando el purgante oficial con las sobras acídulas de una fábrica de gaseosas. (32) El informe de Barreño pone al Presidente furioso, pero no con el Jefe de Sanidad Militar, sino con el médico, por haber descubierto el engaño. (33)

Después del suplicio de Fedina, el Auditor confiesa que él sabía que la muchacha no le habia mentido: "Sus declaraciones me parecian veraces desde el primer momento, y si apreté el tornillo fue para estar más seguro." (138) Pero Fedina ya está destruida y su niño muerto.

El omnisapiente "ticher" -espiritista, teósofo, mago, hipnotista, astrólogo, perito en tesoros ocultos en casas encantadas, y profesor de inglés- nunca ha olvidado los sabios consejos de su tía: "El inglés es más fácil que el latín y más útil, y dar clases de inglés es hacer sospechar a los alumnos que el profesor habla inglés aunque no le entiendan; mejor si no le entienden." (222)

El Presidente Constitucional de la República, autor de innumerables atrocidades, manda a matar al Pelele, pero, por otra parte, regaña a Cara de Angel por no haber sido más caritativo con el idiota: "Alguien que se precia de ser amigo del Presidente de la República no abandona en la calle a un infeliz herido de oculta mano." (39) Cuando "ese animal" no resiste los doscientos "palos" que él mismo le receta, el Presidente paga el entierro para quedar bien con la opinión del pueblo. (40) 
Este laberinto de mentiras particulares es reforzado exteriormente por el interminable chorro de propaganda que contamina el ambiente colectivo. El Gobierno está siempre celebrando la gloriosa labor del Primer Mandatario. Su panegirista oficial, la Lengua de Vaca, pronuncia en el capítulo XVI un elocuentísimo discurso en el cual compara al Presidentc con James Fulton, Juan Montalvo, Juan Santamaría y aun con Jesucristo. Luego, en resumen, la flor de la oratoria nacional declama aigunas de las numerosas virtudes cívicas del Gran Hombre: "¡Viva la Patria! ¡Viva el Presidente Constitucional de la República, Jefe del Partido Liberal, Benemérito de la Patria, Protector de la mujer desvalida, del niño y la instrucción!" (103)

El Presidente, desde luego, no tiene ninguna intención de dejar el poder. Cuando llegan las elecciones, el Gobierno va creando de antemano Ja opinión pública de que el pueblo no necesita ni quiere cambios: "¿Por qué aventurar la barca del Estado en lo que no conocemos, cuando a la cabeza de ella se encuentra el estadista más completo de nuestros tiempos, aquel a quien la historia saludaría Grande entre los Grandes, Sabio entre los Sabios, Liberal, Pensador y Demócrata? CONCIUDADANOS, LAS URNAS OS ESPERAN!! VOTAD!! POR!! NUESTRO!! CANDIDATO!! QUE!! SERA!! REELEGIDO!! POR!! EL!! PUEBLO!!" (226)

De mentira es también el escenario exterior de la novela. El asqueroso Dulce Encanto está adornado con "cadenas de papel azul y blanco". (167) Las ubícuas estaciones de policía encierran toda especie de atrocidades, pero por fuera están decoradas con "banderitas y cadenas de papel de china". (99) La inmunda taberna de la Masacuata ostenta un búcaro de rosas artificiales, tributo a la imagen de una falsa virgen de Chiquinquirá. (72)

El Tirano, pues, no permite nunca que se arraigue la fuerza integrante de la verdad. Dos personas de acuerdo constituirian un nexo social, y los nexos sociales, como hemos visto, trastocan la acción destructora de la Dictadura. La verdad, así como el amor, es una de esas obstracciones que hay que eliminar para que impere el caos.

\section{LA CONFUSIÓN}

Sin medios de contactos sociales y comunicativos, Ios personajes no pueden expresarse ni entenderșe debidamente. Los mendigos, por ejemplo, ya no hablan, sino lloriquean, gimen o ululan como bestias. (10) 
El único que una vez dice algo medio inteligible es el Mosco, pero nadie le contesta ni escucha. (11)

Las prostitutas se pasan el día hablando en jerigonza: "-Indi-pi, a-pa / - ¿уo-pa? Pe-pe, ro-po, chu-pu, la-pa. / - ¿Quitin-que? / -iNa$p a$, lo-pa! / - ¡Na-pa, la-pa!" (166) Tanto cotorrean de este modo, que doña Chón a veces tiene que regañarlas: "¡Cállense, pues, cállense! ¡Qué cosas! Que desde que Dios amanece han de estar ahí chalaca, cbalaca; parecen animales que no entienden." (166)

El tenue vínculo conyugal entre don Benjamín y doña Venjamón es empeorado por las limitaciones temáticas y distenciones lexicográficas de sus pueriles discusiones: "-_Ilógico! ¡Ilógico! ¡Ilógico! / - ¡Relógico! ¡Relógico! ¡Relógico!... / —Relógico! ¡Relógico! ¡Recontralógico! ¡Requetecontrarrelógico!"' (58) El titiritero, además, no puede pronunciar muy bien con su boca desdentada: "Cuando el titiritero se apeaba los dientes postizos, para hablar movía la boca chupada como ventosa." (56) Tan distorsionadas salen sus palabras, que ni su mujer lo entiende: "-Pero, Benjamín, no te entiendo nada -y casi jirimiqueando- $¿ Q u e-$ rrás entender que no te entiendo nada?" (56)

Juan Canales se deshace en cortesías para ganarse la buena voluntad del favorito del Presidente. Pero Cara de Angel no le sigue la corriente, ni lo escucha. "Don Juan perdió control sobre sus nervios al oír que sus palabras caían al vacío." (107) Luego don Juan es el que se tapa los oídos cuando Cara de Angel le presenta el problema de Camila: "Esta vez fue Cara de Angel el que sintió que sus palabras caían al vacío. Tuvo la impresión de hablar a personas que no entendian español." (110)

Abel Carvajal experimenta la misma dificultad cuando trata de apeJar su sentencia de muerte: "La palabra se le deshizo en la boca como pan mojado." (216) Su esposa, por otra parte, balbucea incoherentemente al enterarse de la decisión del jurado: "-i...le, le, le! / No pudo hablar. / -i...le, le, le!". (225) Luego la viuda trata de reclamar el cadáver, pero ya la voz se le ha gastado: "La viuda habló con palabras que no se resolvian en sonidos distintos, sino en un como bisbeo de lector cansado." (241)

Sola en la mazmorra con los restos de su hijo, Fedina lloriquea fragmentos del vocablo que identificaba el vínculo que acaba de perder: "Lamento tras lamento balbucía: Hij! . . Hij! . . Hij! . . (154) Fedina entonces se convierte en la tumba del niño, y no vuelve a hablar. (155)

El vacio de su inesperado enajenamiento deja al general Canales sin habla: "En la respiración se le escapaban restos de palabras, de quejas despedazadas..." (65) Ahora el militar ni siquiera puede comunicarse 
con su hija: "No sé lo que te digo ni tú me entiendes." (68) Camila, asimismo, se queda como sorda y muda, "sin oír bien, sin poder decir otra cosa que, ¡ay Dios mío!" (68)

Aunque Canales y su guía están ligados por la persecución que sufren en común, el indio no entiende nada cuando el general expresa su indignación: "El indio contemplaba al general como un fetiche raro, sin comprender las pocas palabras que decia." (196)

El indio, a su vez, no habla muy bien el castellano. (95) Tampoco dominan la lengua el guardia de Genaro Rodas (242) y los numerosos personajes indios que pasan por la novela ajenos a las costumbres de sus opresores blancos: "aunque municipales, tenían la felicidad de no entender nada de aquello". (227)

Los diálogos entre Cara de Angel, la Masacuata y Lucio Vázquez son tan desarticulados como sus maquinaciones: " $i$ Vos que para todo vas saliendo con ese Genaro Rodas, guacal de hotchata, mi compañero! / - ¿Qué es eso de guacal de horchata? -indagó Cara de Angel. / -Eso es que me parece muerto, que es descoli... ya no sé ni hablar..., descolo-rido, vaya..." / - ¿Y qué tiene que ver? / -Que yo vea no hay inconveniente... / _...Pues, si hay, y perdone, señor que le corte la palabra..." (45)

Camila nunca recibe las cartas de su padre, y la llamada anónima que le echa la culpa de su muerte, no la deja aclarar la verdad: "iNo es verdad, no fue padri...! ¡Aló! ¡Aló! - ya habían cortado la comunicación." (262)

Asimismo se interrumpe el anónimo que le comunica a la viuda de Carvajal el paradero del cadáver de su marido: "Supe que el Auditor se encargó de dar sepultura a los cadá... / La carta se cortaba de golpe, faltaba la continuación." (240)

De vuelta al Tus-Tep, después de haberse pasado la noche tocando inútilmente a la puerta de los Canales, Camila y Cara de Angel se encuentran con un cartero borracho que va dejando caer las cartas por las calles. La pareja le ayuda al borracho a recoger las cartas, y éste, sin comprender nada, le balbucea las gracias: " $¡ M u . .$. chas gra... cias...; le es... digo... que... mu... uchas gra... cias!" (133) Pero los mensajes nunca llegarán. El mensajero, atontado por el narcótico de la Dictadura, los dejará caer de nuevo tan pronto doble la esquina.

Los personajes, en fin, no pueden trasmitir los pocos pensamientos que les quedan. Como no tienen a nadie que los escuche, y la verdad no existe, inexorablemente van perdiendo sus facultades comunicativas $y$, en muchos casos, dejan de pensar del todo. 


\section{EL ESTANCAMIENTO}

Los personajes, pues, quedan física y mentalmente enajenados, y aun dislocados de sus propios seres. Por consiguiente, todo movimiento colectivo o individual es, o termina siendo, divisorio. Fuera del orden caótico de la Dictadura no puede haber nada. Cuando alguien trata de obrar constructivamente, la ausencia de ambiente en qué progresar lo deja suspenso en un vacío. Aparte de ser víctimas o verdugos, los personajes no pueden ni actuar ni existir. $O$ se destruyen o están paralizados. $Y$ esas dos alternativas, las únicas que tienen, al fin y al cabo equivalen a la misma cosa. De ahí que nadie tiene empleo, oficio, pasatiempo ó ideas que sirvan para algún bien propio o social. Ni siquiera hay descansos, refugios, escapes, esperanzas. La pesadilla es siempre y está en todo.

El Presidente y el Auditor, por ejemplo, se dedican exclusivamente a la destrucción del pueblo. No aparecen, en ningún momento, haciendo o pensando en otra cosa. Y su copiosa cuadrilla de soldados y policías nunca protege a los ciudadanos. Al contrario, la Autoridad es quien comete todos los crímenes.

Las prostitutas, en ese mundo deshecho por falta de nexos sinceros, no contribuyen nada con su cariño mercenario. Los pordioseros ni siquiera se ven pidiendo.

La tabernera Masacuata y el cantinero don Lucho, (50) alientan el caos con el licor que le proveen al ofuscado pueblo $y$ al esbirto Lucio Vázquez, quien dedica casi todas sus horas libres a la borrachera. Asimismo el mayor Farfán alterna las atrocidades de su oficio con las orgías y bacanales del Dulce Encanto. (168-169) No hace ninguna otra cosa.

Genaro Rodas, carpintero desempleado, y su esposa Fedina, tienen una tiendecita pero no venden nada. (283) Deshecha la familia, Genaro pasa a ser esbirro de la Dictadura y Fedina, irremediablemente trastornada, termina trabajando en la lavandería del hospital, pero fuera de escena. (283)

El doctor Luis Barreño no puede ejercer su útil profesión, porque la Dictadura no tiene ningún interés en que el pueblo se sane. Todo lo contrario. Eusebio Canales deja de ser general tan pronto aparece en la novela y muere momentos antes de tomar el mando de las fuerzas rebeldes. (260) Su guia indio, campesino de oficio, no puede trabajar porque sus tierras han sido confiscadas por el Gobierno. (195)

En un pasado desconocido, Cara de Angel había sido jefe de un instituto, director de un periódico, diputado, diplomático $\mathrm{y}$ alcalde. (76) 
Pero su actual puesto de favorito y el leitmotif "eta bello y malo como Satán", nos hace sospechar que su modo de proceder en aquellos puestos no fue nada intachable. Su única obra constructiva, la fuga de Canales, surge casi accidentalmente de una misión destructora.

Mintiendo como siempre, el Presidente lamenta el estancamiento social que él mismo está perpetuando para mantenerse en el poder: " $Y$ es así como entre nosotros el industrial se pasa la vida repite y repite: voy a montar una maquinaria nueva, voy a esto, voy a lo otro, a lo de más allá; el señor agricultor, voy a inplantar un cultivo, voy a exportar mis productos; el literato, voy a componer un libro; el profesor, voy a fundar una escuela; el comerciante, voy a intentar tal o cual negocio, y los periodistas - iesos cerdos que a la manteca llaman alma! - vamos a mejorar el país; mas como te decía al principio, nadie hace nada $y$, naturalmente, soy yo, es el Presidente de la República el que lo tiene que hacer todo." (269)

Visto de cerca, el estancamiento global de cada vida $y$, por extensión, la impotencia del orbe social, están constituidos por la totalidad de una scrie continua de frustraciones particulares. Nada provechoso se logra, porque todo esfuerzo resulta ser erróneo, ineficaz, inútil. Si hay metas, siempre están fuera de alcance. Todo progreso se detiene tan pronto como surge.

El Pelele, por ejemplo, nunca puede evitar la crueldad del prójimo: " $L a$ ciudad grande, inmensamente grande para su fatiga, se fue haciendo pequeña para su conjoga." (12) El idiota huye despavorido hacia un refugio que nunca aparece, "como el que escapa de una prisión cuyos muros de niebla a más correr más se alejan." (12)

Frustrada en sus esfuerzos de salvarle la vida a su marido, de recuperar el cadáver, de hablar con el Presidente, la viuda de Carvajal se transforma en una piltrafa sin vida: "Vacía, cavernosa, con una fuerza interna que le paralizaba, en la cama horas enteras alargada como un cadáver, más inmóvil a veces que un cadáver." (238)

Camila también se paraliza al presentir la desaparición de su marido: "Presa entre la mesa y la silla, sin fuerzas para dar el primer paso." (253) Sus desesperados toquidos a la puerta de su tío, (131) y sus diligencias para conseguir un pasaporte, (288) no le dan ningún resultado.

Cara de Angel, detenido por la policía, oye la salida del barco en el cual él creía que se iba a escapar: "El prisionero se tapó los oídos con las manos. Las lágrimas le cegaban. Habia querido romper las puertas, huir, correr, volar, pasar el mar, no ser el que se estaba quedando." (279) 
Aunque el general Canales regresa corriendo a su casa, sufre la sensación de que sus extremidades se han paralizado: "Acababa de cruzar la esquina que ha un minuto viera tan lejos. $Y$ ahora a la que sigue, sólo que ésta... iQué distante a través de su fatiga!... se mordió los dientes para poder con las rodillas. Ya casi no daba paso... tendría que arrastrarse, seguir a su casa por el suelo ayudándose de las manos, de los codos..." (65)

Luego el ejército rebelde que él había organizado, se paraliza al enterarse de su muerte: "La tropa, inmovilizada, lista esa noche para asaltar la primera guarnición, sentía que una fuerza extraña, subterránea, le robaba la movilidad, que sus hombres se iban volviendo de piedra." (260)

Fedina llega demasiado tarde para prevenir a Camila. (91) Chabela no logra proteger a Camila de sus raptores. (78) Don Benjamín presenta una tragedia que resulta ser comiquísima. (58) Luego el Portal del Señor es derrumbado y el titiritero pierde su teatro, su único medio de ganarse la vida. (298)

\section{La ENCARCELACión}

La inmovilización de Cara de Angel culmina en un calabozo subterráneo, "que no daba para cuatro pasos". (291) Asimismo Abel Carvajal es enterrado vivo: "Le sepultaron en una mazmorra de tres varas de largo por dos y media de ancho, en la que habia doce hombres sentenciados a muerte, inmóviles por falta de espacio." (217)

Genaro Rodas, (243) los pordioseros, (15) Niña Fedina, (112) Lucio Vázquez, (217) el estudiante y el sacristán. (16) y muchos otros personajes pasan la mayor parte de la novela atrapados en los muros de algún calabozo.

Áquellos que no están oficialmente encarcelados son restringidos por las circunstancias a espacios sumamente limitados. Chabela nunca sale de su casa. Juan y Judith Canales no se ven fuera de la suya. La Masacuata apenas sale del Tus-Tep. Las prostitutas no se mueven del Dulce Encanto, salvo cuando tres de ellas van con doña Chón a buscar a Fedina. (155) El Presidente no pone un pie en la calle. El doctor Barreño se esconde en un retrete cuando el Tirano lo humilla. (33) Camila se pasa casi toda la novela clausurada, en la casa de su padre, (81) en el TusTep, (124) en su nuevo hogar. (273) Su encerramiento luego se empeora en proporción directa con la atenuación de sus nexos con Cara de Angel: "Desapareció de las habitaciones que daban a la calle sumergida 
por el peso de la pena, que se la fue jalando hacia el fondo de la casa." (286)

La encarcelación y el estancamiento están juntamente representados en la antitesis de los ubicuos vehículos de transporte que andan mucho pero no van a ninguna parte. Cara de Angel, por ejemplo, se encamina hacia el puerto con la angustia de que el tren en que está viajando lo está dejando atrảs: "la sensación confusa de ir en el tren, de no ir en el tren, de irse quedando atrás del tren, cada vez más atrás del tren..." (277) El coche que lo lleva a él y a Camila a la fiesta del Presidente, se convierte de pronto en una prisión, o caja de muerto: "Cara de Angel sacó la cabeza por la portezuela para gritar al cochero que tuviera más cuidado. Este puso los caballos a paso de entierro." (254)

El Pelele sueña con irse de la ciudad en tren, pero la locomotora siempre lo vuelve a traer al mismo lugar: "Pero el tren volvía al punto de partida como un juguete preso de un hilo." (23)

La señora de Carvajal no puede acelerar su coche lo suficiente en su inútil carrera hacia la mansión del Señor Presidente: "Pero el vehículo no rodaba, ella sentía que no rodaba, que las ruedas giraban alrededor de los ejes dormidos, sin avanzar, que siempre estaban en el mismo punto." (220)

Como podemos apreciar, dicha inmovilidad suele estar sadisticamente intensificada con pinceladas de falsa esperanza. En tales casos, la novela deja que las víctimas logren algo, pero en el último instante, cuando creen que ya están a salvo, les da el portazo fatal. La esposa de Carvajal, por ejemplo, está segura de que la detención del Licenciado ha sido un error y que el Señor Presidente lo pondrá en libertad tan pronto como ella le aclare el asunto.

Camila está segura de que su tío le va a abrir la puerta, (130) y felizmente da todos menos el último paso para salir del país. (288) Cara de Angel no ve la cortedad de su pihuela y huye sin darse cuenta del tirón que lo espera en el puerto de partida. (279) Abel Carvajal, como es inocente, está convencido de que el coche que lo lleva al calabozo de los condenados a muerte lo va a dejar en su casa. (214) La revolución del general Canales se lleva a cabo sin trabas hasta el primer momento de la batalla. (260)

No hay, pues, movimiento definitivo ni verdadera esperanza. Esa es la ley y ahí está el Auditor de Guerra para imponerla: "¿Cuándo entenderés que no hay que dar esperanzas? En mi casa, lo que todos debemos saber, hasta el gato, es que no se dan esperanzas de ninguna especie a nadie." (244) 


\section{RESUMEN}

La complejidad de causas y efectos que constituyen la estructura interior de El Señor Presidente, se resuelve en un desproporcionado proceso de desintegración social. No hay nada positivo, y parte del mecanismo del todo negativo está articulado por el encadenamiento de adversidades que hemos apuntado: el enajenamiento del individuo produce y es resultado de la desunión social; la desunión social produce y es resultado de la mentira; la mentira, de la cofusión; la confusión, del estancamiento; el estancamiento, de la encarcelación; la encarcelación, del enajenamiento; y así sucesivamente en un ciclo infernal.

Asturias, entonces, no inventa nada, sino que desnuda la realidad de una dictadura hispanoamericana para que el lector le vea bien las entranas. $\mathrm{Y}$ como no fija ni espacio ni tiempo ni hechos particulares, esa misma visión se presta fácilmente para esclarecer la esencia de cualquier tiranía.

West Virginia University

Carlos Navarro 